\title{
Extrafacial Lentigo Maligna: A Clinical And Dermoscopic Analysis According to Localization
}

\author{
Gabriel Salerni ${ }^{1}$, Emilia Cohen-Sabban ${ }^{2}$, Horacio Cabo ${ }^{3}$
}

\begin{abstract}
1 Dermatology Department, Hospital Provincial del Centenario de Rosario, Universidad Nacional de Rosario, Diagnóstico Médico Oroño, Rosario, Argentina

2 Dermatology Service, Instituto de Investigaciones Médicas Alfredo Lanari, Universidad de Buenos Aires, Argentina

3 Dermatology Department, Universidad de Buenos Aires, Argentina
\end{abstract}

Key words: skin cancer, melanoma, lentigo maligna, dermoscopy

Citation: Salerni G, Cohen-Sabban E, Cabo H. Extrafacial lentigo maligna: a clinical and dermoscopic analysis according to localization. Dermatol Pract Concept. 2022;12(1):e2022035. DOI: https://doi.org/10.5826/dpc.1201a35

Accepted: August 30, 2021; Published: January 2022

Copyright: (02022 Salerni et al. This is an open-access article distributed under the terms of the Creative Commons

Attribution-NonCommercial License (BY-NC-4.0), https://creativecommons.org/licenses/by-nc/4.0/, which permits unrestricted noncommercial use, distribution, and reproduction in any medium, provided the original authors and source are credited.

Funding: None.

Competing interests: None.

Authorship: All authors have contributed significantly to this publication

Corresponding author: Gabriel Salerni, MD, Dermatology Department, Hospital Provincial del Centenario de Rosario - Universidad Nacional de Rosario - Diagnóstico Médico Oroño, Rosario, Argentina. Email: gabrielsalerni@hotmail.com

\footnotetext{
ABSTRACT Introduction: Whether extrafacial lentigo maligna (EFLM) differs clinically and/or dermoscopically according to location has not been analyzed in depth.

Objectives: To evaluate clinical and dermoscopic characteristics regarding different localization in a series of EFLM.

Methods: We conducted a retrospective analysis of clinical and dermoscopic characteristics of 69 histologically proven EFLM retrieved from the database of two private institutions.

Results: Of the 69 EFLM included in the study, 25 (36.2\%) were located in posterior trunk (PT), 16 $(23.2 \%)$ in anterior trunk (AT), $15(21 \%)$ in upper extremities (UE), and $13(18.8 \%)$ in lower extremities (LE). Mean diameter among localization were as follows: $14.3 \mathrm{~mm}$ in PT, $11.8 \mathrm{~mm}$ in AT, $14 \mathrm{~mm}$ in UE, and $10 \mathrm{~mm}$ in LE ( $\mathrm{p}$ 0.44). The most frequent dermoscopic criteria were angulated lines and tan structureless areas $(70 \%)$, followed by atypical pigment network $(60 \%)$, both with similar distribution among groups. Angulated lines pattern was the most frequent global pattern, observed in 55\% of cases. Tan structureless/granularity pattern and patchy peripheral pigmented islands pattern were seen in $15.6 \%$ and $11.6 \%$ cases, respectively. No statistically significant differences were observed in the distribution of global dermoscopic pattern in the different localizations.

Conclusions: From the clinical point of view, EFLM did not differ in terms of patient's age and diameter regarding localization. Upon dermoscopy, we found no significant differences in the overall dermoscopic pattern in the different localizations.
} 


\section{Introduction}

Lentigo maligna (LM) is a variant of in situ melanoma that develops mainly in chronic sun exposure areas in middle-aged and elderly patients. If left untreated, it can evolve to its invasive form, LM melanoma [1]. Hence, early recognition and proper management is crucial to reduce morbidity and mortality associated to melanoma.

Dermoscopy has shown to increase the sensitivity and specificity in the clinical diagnosis of melanoma by allowing the visualization of diagnostic criteria not visible to naked eye. Moreover, its routine use for the evaluation of melanocytic and non-melanocytic skin lesions is recommended in most of the clinical guidelines worldwide [2,3]. Dermoscopic criteria such as granularity, angulated lines, or vessels as well as overall dermoscopic patterns have been described to improve recognition of lentigo maligna in nonfacial chronically sun-damaged skin [4].

\section{Objectives}

We sought to evaluate clinical and dermoscopic characteristics regarding different localization in a series of extrafacial lentigo maligna (EFLM) confirmed by histopathology.

\section{Methods}

We conducted a retrospective analysis of clinical and dermoscopic characteristics of 69 histologically proven EFLM diagnosed between 2016 and 2020 in two private clinics. The study included primary LM with clinical and dermoscopic pictures of acceptable quality to allow reliable evaluation. Dermoscopic images were captured with polarized light using hand-held dermatoscope (Dermlite II pro Hybrid, 3Gen LLC) attached to a digital camera and digital dermoscopy devices (FotoFinder Systems GmbH).

The study was conducted according to the Declaration of Helsinki; patient's written consent was obtained for all invasive procedures.

Epidemiological data such as age and gender of the patients and clinical data the localization and diameter of the lesions were incorporated along with the clinical and dermoscopic images in a PowerPoint presentation (Microsoft Corp). This collection was presented to 2 dermatologists with experience in dermoscopy (G.S. and H.C.) who performed both clinical and dermoscopic evaluation. Dermoscopic images were assessed for the presence or absence of criteria for melanoma previously described in nonfacial skin [4-6].

\section{Statistical Analysis}

The $\chi^{2}$ test was used to compare qualitative variables, and the $t$ test was used to compare means. Differences were set as statistically significant at $\mathrm{P} \leq 0.05$.

\section{Results}

Of the 69 EFLM included in the study, $25(36.2 \%)$ were located in posterior trunk (PT), $16(23.2 \%)$ in anterior trunk (AT), 15 (21\%) in upper extremities (UE), and 13 (18.8\%) in lower extremities (LE).

\section{Population}

The study population consisted of 24 females $(34.8 \%)$ and 45 males $(65.2 \%)$, with a mean age of 68.5 years (range $38-86)$. No statistically significant differences were observed in age according to localization (Figure 1). Distribution according to gender was homogeneous among the 4 groups.

\section{Clinical Evaluation}

Mean diameter among localization were as follows: $14.3 \mathrm{~mm}$ (5-24 mm) in PT, $11.8 \mathrm{~mm}$ (6-23 mm) in AT, $14 \mathrm{~mm}$ (2-30 mm) in UE, and $10 \mathrm{~mm}$ (range 4-24 mm) in LE (Figure 2). No statistically significant differences were observed regarding diameter and localization $(\mathrm{P}=0.44)$. EFLM in individuals older than 70 years showed a significantly greater diameter than in those younger than 70 years $(\mathrm{P}=0.002)$.

In clinical examination (Table 1), 60 out of the 69 EFLM included $(87 \%)$ were considered striking from the clinical point of view. Concerning localization, all lesions located in UE were considered clinically striking, $92 \%$ of the lesions in PT, $80 \%$ in AT, and $70 \%$ in LE, respectively. Light brown and dark brown were the most frequent colors, observed in about the $90 \%$ of the cases. White, blue-grey and pink were the less frequent colors observed clinically. Lesions located in AT displayed only

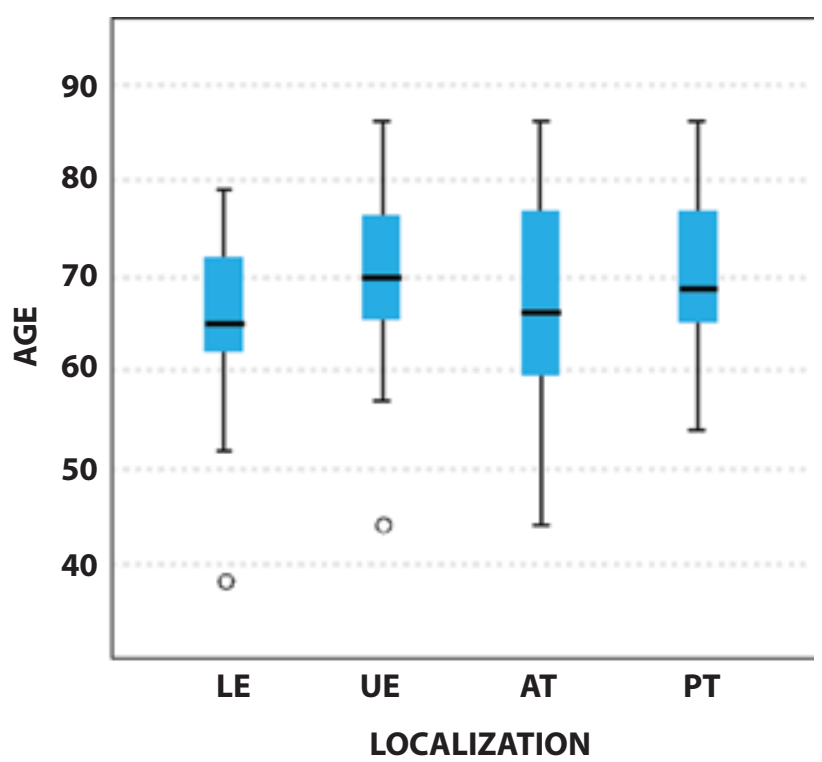

Figure 1. Age distribution is similar among localization categories (Kruskal-Wallis test, $\mathrm{P}=0.343$ ).

$\mathrm{LE}=$ lower extremities; UE = upper extremities; $\mathrm{AT}=$ anterior trunk; PT = posterior trunk 


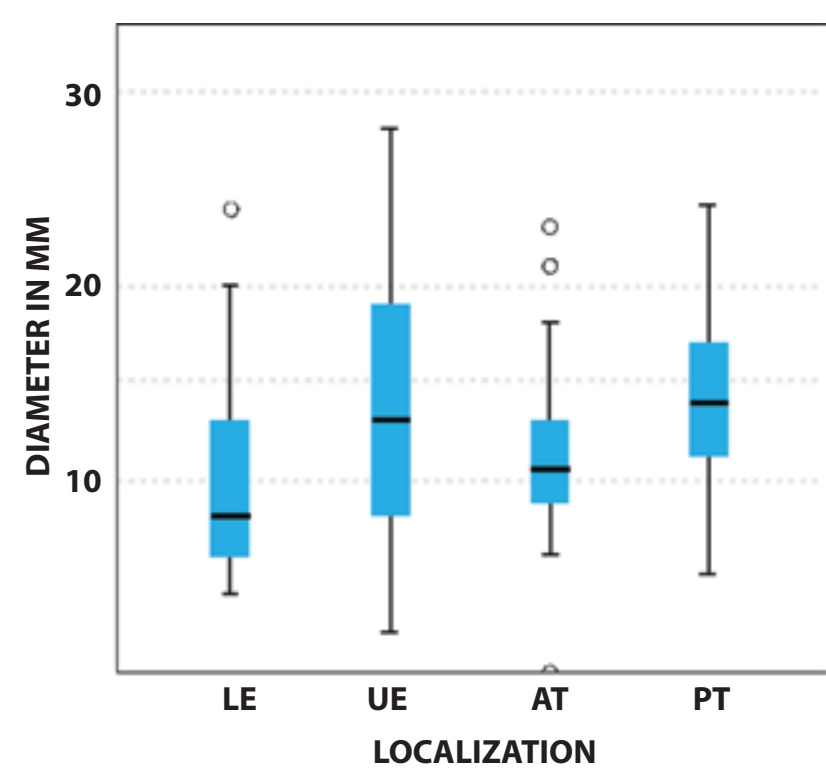

Figure 2. Diameter distribution is similar among localization categories (Kruskal-Wallis test, $\mathrm{P}=0.44$ ).

LE=lower extremities; UE=upper extremities; AT=anterior trunk; PT=posterior trunk

3 colors: light brown, dark brown and blue-grey, while in the other localizations at least 5 colors were observed.

\section{Dermoscopic Evaluation}

The dermoscopy evaluation findings are shown in Table 2. The most frequent dermoscopic criteria were angulated lines and tan structureless areas, observed in more than three quarters of all the EFLM analyzed, with quite similar distribution among the different localizations. Atypical pigment network was observed in $60 \%$ of all the EFLM, also with similar observation among groups. Hyperpigmented follicular pigmentation was observed in almost one third of the cases, being less frequent in PT. Aggregated dots were seen in less than $20 \%$ of the EFLM, being more frequent in AT. Bluewhite veil and negative pigment network were observed in $6 \%$ of the cases; none of the EFLM displayed circle within circle criteria. Only 1 lesion located in TP showed radial projections.

Almost half of the EFLM showed regression structures: $36.2 \%$ granularity and $23.2 \%$ scar-like areas; regression structures were less frequent in LE.

Dotted and polymorphous vessels were the most frequent vascular pattern observed (15.9\% and $11.6 \%$, respectively). Serpentine vessels and milky-red areas were observed in $7 \%$ of all EFLM, with similar distribution among different localizations, but milky-red areas criterion was not observed in LE. None of the melanomas included showed red globules.

Near half of the EFLM displayed dermoscopic criteria for seborrheic keratosis, being more frequent in PT and UE, but no statistically significant differences were observed regarding localization.

The 6 colors were observed in all localizations upon dermoscopy. Light brown was observed in all cases, and dark brown in 66 out of 69 lesions. Blue-grey color was present in more than half of the lesions, with similar distribution regarding localization. Pink, white, and black colors were seen in near $40 \%$ of all EFLM. Pink and white colors were more frequent in PT and UE. Black color was more frequent in LE.

Global dermoscopic pattern analysis is shown in Table 3. Angulated lines pattern was the most frequent pattern, observed in $55 \%$ of cases. Tan structureless/granularity pat-

Table 1. Clinical Characteristics.

\begin{tabular}{|c|c|c|c|c|c|}
\hline & $\begin{array}{c}\text { Lower } \\
\text { extremities } \\
\text { n (\%) }\end{array}$ & $\begin{array}{c}\text { Upper } \\
\text { extremities } \\
n(\%)\end{array}$ & $\begin{array}{c}\text { Anterior trunk } \\
\text { n (\%) }\end{array}$ & $\begin{array}{c}\text { Posterior } \\
\text { trunk } \\
\text { n (\%) }\end{array}$ & $\begin{array}{l}\text { Total } \\
\text { n (\%) }\end{array}$ \\
\hline Cases & $13(18.8)$ & $15(21.7)$ & $16(23.2)$ & $25(36.2)$ & $69(100)$ \\
\hline \multicolumn{6}{|l|}{ Colors } \\
\hline Light brown & $11(84.6)$ & $14(93.3)$ & $15(93.7)$ & $23(92)$ & $63(91.3)$ \\
\hline Dark brown & $12(92.3)$ & $13(86.6)$ & $13(81.2)$ & $24(96)$ & $62(89.9)$ \\
\hline Pink & $3(23)$ & $3(20)$ & $0(0)$ & $2(8)$ & $8(11.6)$ \\
\hline Blue-gray & $1(7.7)$ & $2(13.3)$ & $2(12.5)$ & $0(0)$ & $5(7.2)$ \\
\hline White & $0(0)$ & $1(6.6)$ & $0(0)$ & $2(8)$ & $3(4.3)$ \\
\hline Black & $5(38.4)$ & $5(33.3)$ & $0(0)$ & $7(28)$ & $17(24.6)$ \\
\hline \multicolumn{6}{|l|}{ Borders } \\
\hline Ill defined & $6(46.1)$ & $6(40)$ & $8(50)$ & $20(80)$ & $41(59.4)$ \\
\hline Well defined, irregular & $5(38.4)$ & $9(60)$ & $7(43.5)$ & $5(20)$ & $26(37.7)$ \\
\hline Well defined, regular & $2(15.4)$ & $0(0)$ & $0(0)$ & $0(0)$ & $2(2.9)$ \\
\hline Striking lesion & $9(69.2)$ & $15(100)$ & $13(81.2)$ & $23(92)$ & $60(87)$ \\
\hline
\end{tabular}


Table 2. Dermoscopic Characteristics.

\begin{tabular}{|c|c|c|c|c|c|}
\hline & $\begin{array}{l}\text { Lower } \\
\text { extremities n (\%) }\end{array}$ & $\begin{array}{c}\text { Upper } \\
\text { extremities n (\%) }\end{array}$ & $\begin{array}{c}\text { Anterior } \\
\text { trunk n (\%) }\end{array}$ & $\begin{array}{c}\text { Posterior } \\
\text { trunk n (\%) }\end{array}$ & $\begin{array}{l}\text { Total } \\
\text { n (\%) }\end{array}$ \\
\hline Cases & $13(18.8)$ & $15(21.7)$ & $16(23.2)$ & $25(36.2)$ & $69(100)$ \\
\hline Angulated lines & $13(100)$ & $11(73.3)$ & $12(75)$ & $17(68)$ & $53(76.8)$ \\
\hline Aggregated dots & $2(15.4)$ & $1(6.6)$ & $5(31.2)$ & $4(16)$ & $12(17.4)$ \\
\hline Atypical pigment network & $8(61.5)$ & $8(53.3)$ & $10(62.5)$ & $15(60)$ & $41(59.4)$ \\
\hline $\begin{array}{l}\text { Asymmetric perifollicular } \\
\text { hyperpigmentation }\end{array}$ & $5(38.4)$ & $7(46.6)$ & $7(43.5)$ & $2(8)$ & $21(30.4)$ \\
\hline Peripheral tan structureless areas & $10(76.9)$ & $12(80)$ & $14(87.5)$ & $18(72)$ & $54(78.3)$ \\
\hline Negative network & $0(0)$ & $2(13.3)$ & $0(0)$ & $2(8)$ & $4(5.8)$ \\
\hline Circle within circle & $0(0)$ & $0(0)$ & $0(0)$ & $0(0)$ & $0(0)$ \\
\hline Blue-white veil & $1(7.7)$ & $1(6.6)$ & $1(6.2)$ & $1(4)$ & $4(5.8)$ \\
\hline \multicolumn{6}{|l|}{ Streaks } \\
\hline Pseudopods & $0(0)$ & $0(0)$ & $0(0)$ & $0(0)$ & $0(0)$ \\
\hline Radial projections & $0(0)$ & $0(0)$ & $0(0)$ & $1(4)$ & $1(1.4)$ \\
\hline \multicolumn{6}{|l|}{ Vascular structures } \\
\hline Dotted vessels & $3(23)$ & $5(33.3)$ & $0(0)$ & $3(12)$ & $11(15.9)$ \\
\hline Serpentine vessels & $1(7.7)$ & $3(20)$ & $1(6.2)$ & $1(4)$ & $6(8.7)$ \\
\hline Polymorphous vessels & $2(15.4)$ & $3(20)$ & $1(6.2)$ & $2(8)$ & $8(11.6)$ \\
\hline Milky-red areas & $0(0)$ & $2(13.3)$ & $1(6.2)$ & $2(8)$ & $5(7.2)$ \\
\hline Red globules & $0(0)$ & $0(0)$ & $0(0)$ & $0(0)$ & $0(0)$ \\
\hline \multicolumn{6}{|l|}{ White shiny structures } \\
\hline Shiny white lines & $2(15.4)$ & $2(13.3)$ & $1(6.2)$ & $2(8)$ & $7(10.1)$ \\
\hline White shiny areas & $0(0)$ & $0(0)$ & $0(0)$ & $0(0)$ & $0(0)$ \\
\hline Rosettes & $0(0)$ & $0(0)$ & $0(0)$ & $0(0)$ & $0(0)$ \\
\hline \multicolumn{6}{|l|}{ Regression structures } \\
\hline Absence & $11(84.6)$ & $8(53.3)$ & $8(50)$ & $10(40)$ & $37(53.6)$ \\
\hline Granularity or peppering & $2(15.4)$ & $5(33.3)$ & $7(43.5)$ & $11(44)$ & $25(36.2)$ \\
\hline Scar-like areas & $0(0)$ & $4(26.6)$ & $3(18.7)$ & $9(36)$ & $16(23.2)$ \\
\hline \multicolumn{6}{|l|}{ Prominent skin markings } \\
\hline Criteria for seborrheic keratosis & $4(30.7)$ & $8(53.3)$ & $6(37.5)$ & $15(60)$ & $33(47.8)$ \\
\hline \multicolumn{6}{|l|}{ Colors } \\
\hline Light brown & $13(100)$ & $15(100)$ & $16(100)$ & $25(100)$ & $69(100)$ \\
\hline Dark brown & $13(100)$ & $15(100)$ & $16(100)$ & $24(96)$ & $66(98.6)$ \\
\hline Pink & $3(23)$ & $8(53.3)$ & $5(31.2)$ & $14(56)$ & $30(43.5)$ \\
\hline Blue-gray & $7(53.8)$ & $9(60)$ & $9(56.2)$ & $12(48)$ & $37(53.6)$ \\
\hline White & $3(23)$ & $7(46.6)$ & $5(31.2)$ & $12(48)$ & $27(39.1)$ \\
\hline Black & $6(46.1)$ & $6(40)$ & $5(31.2)$ & $8(32)$ & $25(36.2)$ \\
\hline
\end{tabular}

Table 3. Dermoscopic Patterns

\begin{tabular}{|l|c|c|c|c|c|c|} 
& $\begin{array}{c}\text { Lower } \\
\text { extremities } \mathbf{n ~ ( \% )}\end{array}$ & $\begin{array}{c}\text { Upper } \\
\text { extremities n (\%) }\end{array}$ & $\begin{array}{c}\text { Anterior } \\
\text { trunk n (\%) }\end{array}$ & $\begin{array}{c}\text { Posterior } \\
\text { trunk n (\%) }\end{array}$ & $\begin{array}{c}\text { Total } \mathbf{n} \\
\mathbf{( \% )}\end{array}$ & $\begin{array}{c}\mathbf{P} \\
\mathbf{P}\end{array}$ \\
\hline Cases per localization & $13(18.8)$ & $15(21.7)$ & $16(23.2)$ & $25(36.2)$ & $69(100)$ & \\
\hline Global dermoscopic pattern & & & & & & \\
\hline $\begin{array}{l}\text { Patchy peripheral pigmented } \\
\text { islands }\end{array}$ & $0(0)$ & $2(13.3)$ & $3(18.7)$ & $3(12)$ & $8(11.6)$ & 0.62 \\
\hline Angulated lines & $8(61.5)$ & $7(46.7)$ & $7(43.7)$ & $16(64)$ & $38(55.1)$ & 0.64 \\
\hline $\begin{array}{l}\text { Tan structureless and } \\
\text { granularity }\end{array}$ & $2(15.4)$ & $1(6.7)$ & $4(25)$ & $4(16)$ & $11(15.9)$ & 0.59 \\
\hline None & $3(23.1)$ & $5(33.3)$ & $2(12.5)$ & $2(8)$ & $12(17.4)$ & 0.19 \\
\hline
\end{tabular}




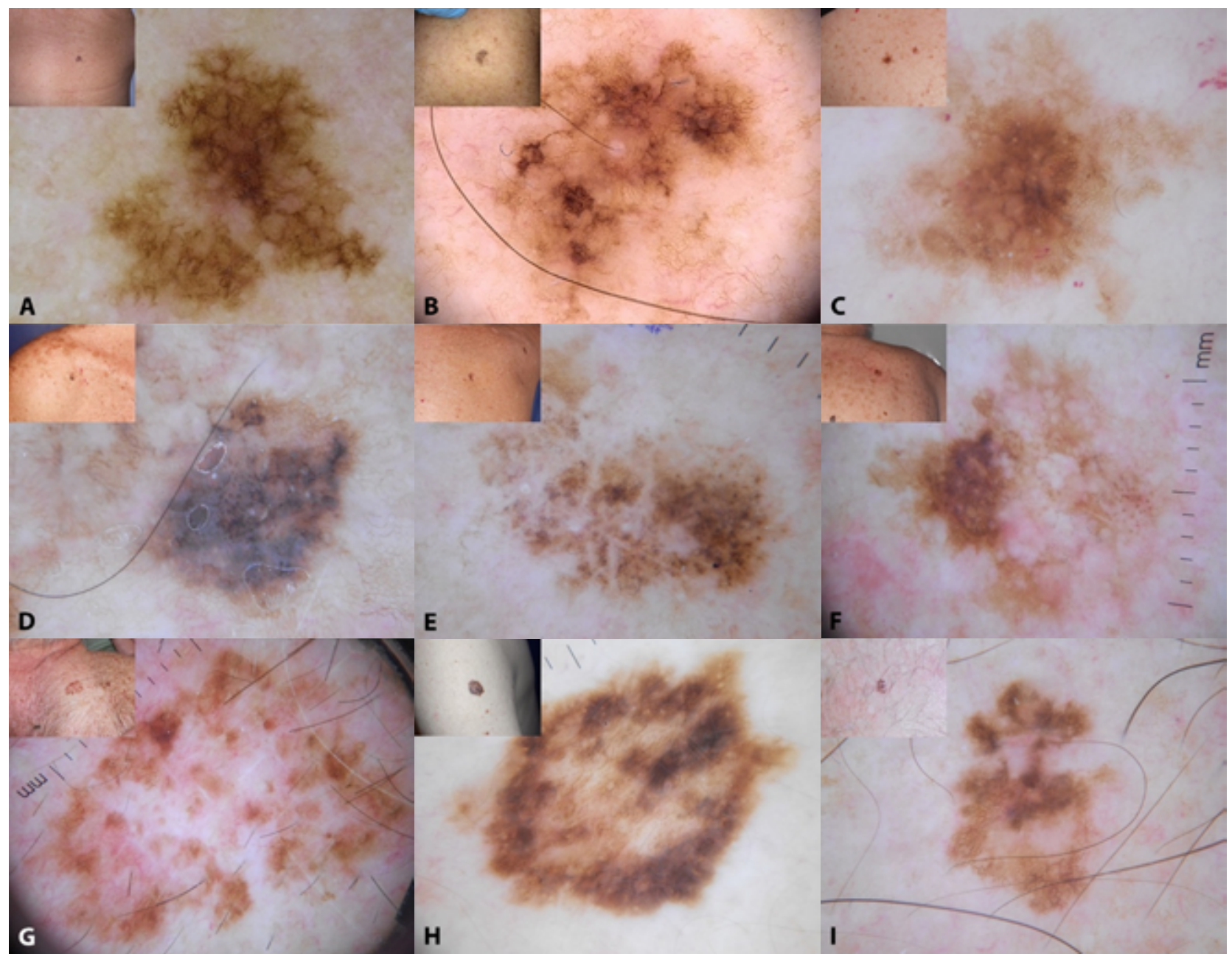

Figure 3. Global dermoscopic pattern. (A-C) Angulated lines, (D-F) granularity (middle row), (G-I) and patchy peripheral pigmented islands.

Table 4. Number of Colors in the Clinical and Dermoscopic Examination

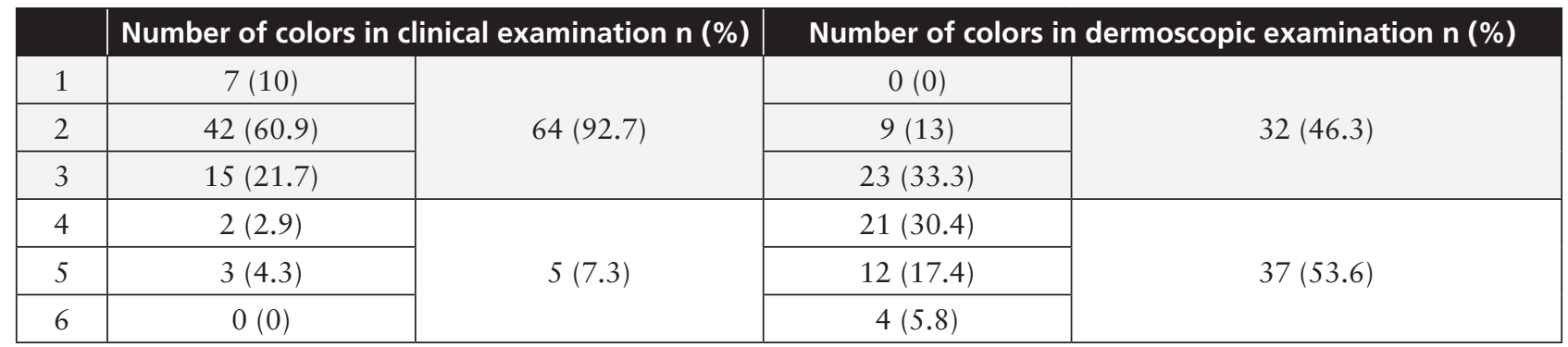

$\mathrm{P}<0.001$

tern and patchy peripheral pigmented islands pattern were seen in the $15.6 \%$ and $11.6 \%$ of cases, respectively (Figure 3 ). Twelve of 69 lesions (17.3\%) showed none of these global patterns. No statistically significant differences were observed in the distribution of global dermoscopic pattern in the different localizations.

\section{Colors Upon Clinical versus. Dermoscopic Evaluation}

Table 4 shows number of colors observed upon clinical and dermoscopic examination. With the use of dermoscopy, the percentage of melanomas displaying at least 4 colors raised from $7.3 \%$ to $53.6 \%(\mathrm{P}<0.001)$

\section{Conclusions}

LM is a distinct form of melanoma in situ, which is characterized by an increased number of histologically atypical melanocytes situated along the dermo-epidermal junction. It mainly develops in middle-age and elderly individuals on chronically sun exposed areas. Although LM can precede by many years the dermal invasion, rapid progression has been 
described $[7,8]$. Therefore, early diagnosis and appropriate treatment are essential to improve prognosis. Whether EFLM differs clinically and/or dermoscopically according to location has not been analyzed in depth.

The clinical diagnosis of EFLM can be challenging since it can simulate other conditions especially solar lentigo or pigmented actinic keratosis. In our study, 90\% of the EFLM were striking from the clinical point of view; the lesions were clinically polychromatic (at least 3 colors) and with a similar diameter regardless of location. Lesions tend to have a greater diameter in upper extremities and posterior trunk, but differences were not statistically significant.

Dermoscopy has become a key diagnostic tool to enhance both sensitivity and specificity in the clinical diagnosis of melanoma [2,3]. The dermoscopic criteria of LM and its invasive form, LM melanoma, were first described in facial location. Furthermore, a progression model for facial LM has been well established and has been widely accepted [9]. More recently, dermoscopic features of LM in extrafacial location were described [4-6]. In 2013, Keir reported that the global criterion of lentigo-like pigment pattern lacking a lentigo-like border, combined with the criteria of asymmetrically pigmented follicular openings and large polygons detected the great majority of melanoma in his series of 20 cases (18 in situ) [5]. Jaimes et al described and analyzed the clinical and dermoscopic characteristics of both in situ and invasive melanomas on nonfacial chronically sun-damaged skin; they concluded that outlier lesions manifesting dermoscopic structures, such as granularity, angulated lines, or vessels and any of the 3 described dermoscopic patterns: patchy peripheral pigmented islands, angulated lines pattern and tan structureless and granularity pattern should raise suspicion for melanoma.

In our series, peripheral tan structureless areas, angulated lines and atypical pigment network were the most frequent dermoscopic criteria observed. Angulated lines were more frequent in LE, where they were observed in all cases; conversely, tan structureless areas and atypical pigment network had similar distribution among different localizations. Asymmetric perifollicular hyperpigmentation was much less frequent in PT. Aggregated dots was more frequent in AT. Regression structures were less frequently observed in LE: granularity was observed in only 2 cases, and none showed scar-like areas. In PT regression structures were more prevalent. All vascular structures evaluated were more frequent in UE than in other locations. Shiny white lines, the only white shiny structure observed, were more frequent in extremities than in the trunk. Almost half of the EFLM in the series showed dermoscopic criteria for seborrheic keratosis, this was more frequently reported in UE and PT. No statistically significant differences were observed in the overall dermoscopic pattern distribution according to localization.

Our study does not lack of limitations due to its retrospective design, the lack of control groups and the fact that evaluators were not blinded to the diagnoses. Additionally, selection and verification bias may lead to an overestimation of specificity of dermoscopic criteria in the diagnosis of EFLM.

We believe that this study provides useful and valuable information to learn more about the dermoscopic aspects of EFLM and to improve early detection, especially by providing relevant information for the identification of the most prevalent dermoscopic criteria in different locations.

In this study we evaluated clinical and dermoscopic aspect in a series of 69 EFLM according to localization. From the clinical point of view, EFLM did not differ in terms of patient age and diameter regarding localization. Upon dermoscopy, angulated lines were more frequent in LE, aggregated dots were more frequent in AT, regression structures were more prevalent in PT, asymmetric perifollicular hyperpigmentation was much less frequent in PT, vascular structures were more frequent in UE, white shiny lines were more frequently observed in extremities than in the trunk. We found no significant differences in the overall dermoscopic pattern in the different localizations.

\section{References}

1. Clark WH, Mihm MC. Lentigo maligna and lentigo-maligna melanoma. Am J Pathol. 1969;55(1):39-67. PMID: 5776171. PMCID: PMC2013384.

2. Bafounta ML, Beauchet A, Aegerter P, Saiag P. Is dermoscopy (epiluminescence microscopy) useful for the diagnosis of melanoma? Results of a meta-analysis using techniques adapted to the evaluation of diagnostic tests. Arch Dermatol. 2001;137:1343-1350. DOI: 10.1001/archderm.137.10.1343. PMID: 11594860.

3. Kittler H, Pehamberger H, Wolff K, Binder M. Diagnostic accuracy of dermoscopy. Lancet Oncol. 2002;3:159-165. DOI: 10.1016/ s1470-2045(02)00679-4. PMID: 11902502.

4. Jaimes N, Marghoob AA, Rabinovitz H, et al. Clinical and dermoscopic characteristics of melanomas on nonfacial chronically sun-damaged skin. J Am Acad Dermatol. 2015 Jun;72(6):1027-1035. DOI: 10.1016/j.jaad.2015.02.1117. PMID: 25824275.

5. Keir J. Dermatoscopic features of cutaneous non-facial non-acral lentiginous growth pattern melanomas. Dermatol Pract Concept. 2014;4(1):77-82. DOI: 10.5826/dpc.0401a13. PMID: 24520520. PMCID: PMC3919846.

6. Lau YN, Affleck AG, Fleming CJ. Dermatoscopic features of extrafacial lentigo maligna. Clin Exp Dermatol. 2013;38(6):612616. DOI: 10.1111/ced.12063. PMID: 23837933.

7. Michalik EE, Fitzpatrick TB, Sober AJ. Rapid progression of lentigo maligna to deeply invasive lentigo maligna melanoma. Report of two cases. Arch Dermatol. 1983119(10):831-835. PMID: 6614952. 
8. Kilinc-Karaarslan I, Akalin T, Ozdemir F. Lentigo maligna melanoma with folliculotropism: dermoscopic features during rapid progression. Arch Dermatol. 2009;145(6):725-726. DOI: 10.1001/archdermatol.2009.101. PMID: 19528438.
9. Stolz W, Schiffner R, Burgdorf WH. Dermatoscopy for facial pigmented skin lesions. Clin Dermatol. 2002;20(3):276-278. DOI: 10.1016/s0738-081x(02)00221-3. PMID: 12074867. 